\title{
Studying the effects of deficit irrigation as an on-farm strategy on carrot yield in arid environment
}

\author{
Kamel Nagaz $^{1 *}$, Fathia El Mokh ${ }^{1}$, Mohamed Moncef Masmoudi ${ }^{2}$ and Netij Ben Mechlia ${ }^{2}$ \\ ${ }^{1}$ Institut des Régions Arides, 4119 Médenine, Tunisia \\ ${ }^{2}$ INAT, 43 avenue Charles Nicolle, 2083 Tunis, Tunisia
}

\begin{abstract}
The deficit irrigation (DI) as an on-farm water management strategy was tested for 3years to determine the water requirements and productivity, soil salinity and yield for carrot irrigated with saline water $(3.6 \mathrm{dS} / \mathrm{m})$ under actual farming conditions in southern Tunisia. The irrigation regimes were full (1100) and deficit (180 and I60) irrigated with levels of 100, 80 and $60 \%$ of ETc when the readily available water, $35 \%$ of total available water (TAW), in the 1100 treatment was depleted, and traditional farmer practice (Farmer). Regulated DI regime where $40 \%$ reduction is applied only during ripening stage (160-ripening) was also used. Higher soil salinity is observed at harvest under 160 and Farmer treatments compared to 1100 . Carrot yield was highest over 3 years for the I100 scheduling technique, (29.5, 28.7 and $26.8 \mathrm{t} / \mathrm{ha}$ ) although no significant differences were observed with the 160-ripening strategy. However, the 180 and 160 treatments caused significant reductions in carrot yields through a reduction in roots number and weight in comparison with I100. The farmer's method not only caused significant reductions in yield but also resulted in using 43 to $57 \%$ more water and increased soil salinity. For all treatments, carrot yields were higher in first than the two following years. Water productivity (WP) values reflected this difference and varied between absolute extremes of 3.3 and $9.7 \mathrm{~kg} / \mathrm{m}^{3}$. WP was the greatest in the 160 treatment and the least in the Farmer's strategy. 1100 irrigation strategy provides significant advantage on yield and WP compared to farmer's method in carrot production. Therefore, for water-saving purposes, the 1100 irrigation scheduling is recommended to optimize the use of saline water in carrot production and to control soil salinity. Nonetheless, under water scarcity, irrigation of carrot could be scheduled using 160-ripening and 180 deficit strategies, with some yield reductions (4-15\%).
\end{abstract}

Key words: salinity, deficit irrigation, carrot, yield, water productivity

\section{INTRODUCTION}

Limited supply of good quality water is a major constraint to crop production in the Mediterranean region of Tunisia. Presently, there is an increasing pressure to use saline water to intensify agriculture in the arid part of Tunisia. Irrigation of a wide range of crops such as potatoes, lettuces, fava beans and carrots is increasing around shallow wells having a salinity more than $3 \mathrm{dS} / \mathrm{m}$. Production systems based on crops that are not tolerant to salinity in arid regions would not be sustainable without proper management of both water and salt.

Good management of irrigation water is required for farmers seeking a viable mean to maximize water use. Many studies have reported substantial increases in crop yields as a result of suitable irrigation management, including studies in saline conditions (Jalota et al., 2006; Zhang et al., 2004; Paradiso et al., 2002; Malash et al., 2005; Nagaz et al., 2007). It has been demonstrated that optimal irrigation scheduling requires accurate estimates of crop evapotranspiration (ETc) (Doorenbos and Pruitt. 1977).

Irrigated farming in arid lands is also subject to the danger of an accumulation of salinity in the soils. Therefore, good management should take into consideration the effect of irrigation on the crop yield and at the same time on the environment, particularly the risk of soil degradation. Considerable research has been directed towards defining the effects of salts upon crop growth and development (Maas, 1990; Shannon et al., 1999). The available information is

\footnotetext{
* Corresponding author: nagaz.kameleddine@ira.rnrt.tn
} 
impressive but should be adapted to the local environment. Carrot (Daucus carota L.) is considered relatively susceptible to salinity (Bernstein et al., 1974) and an important short duration root vegetable grown for fresh market food. Carrot is grown in arid regions of Tunisia during autumn and winter periods which coincide with the rainy season and irrigated with well waters. Because carrot is high value crop, the best irrigation management strategy is to maximize yield by supplying the irrigation requirement of the crop. However, irrigation is applied by farmers using empirical knowledge without scheduling and application of water often exceeds crop requirements.

The impact of irrigation scheduling with saline water on carrot yield and quality has not been studied in arid regions of Tunisia. To gain information on water requirements of carrot crop, field investigations were initiated in 2007 with the objective to determine irrigation water requirements of carrot crop and to make quantitative assessments of both salt accumulation in the soil and yield response to water supply in relation to deficit irrigation strategies with saline water in order to derive an irrigation strategy that save water in irrigated carrot, reduce salt input and improve crop water productivity under the arid Mediterranean conditions of southern Tunisia.

\section{MATERIALS AND METHODS}

A Field experiment was conducted during the fall-winter carrot growing seasons over 3 years (2007-08 to 2009-10) in a private farm situated in the region of Médenine (Tunisia). The climate is typical of arid areas and the rainfall during the growing season of carrot for 3 years is reported in figure 1. Most of the rainfall occurred during September, October and January.

The soil is a sandy soil with low organic matter content. The electrical conductivity (ECe) values measured before planting are, respectively, 3.74, 3.2 and $3.7 \mathrm{dS} / \mathrm{m}$ for first, second and third year of carrot crop. The total soil available water calculated between field capacity and wilting point for an assumed carrot root extracting depth of 0.80 $\mathrm{m}$, was $100.5 \mathrm{~mm}$.

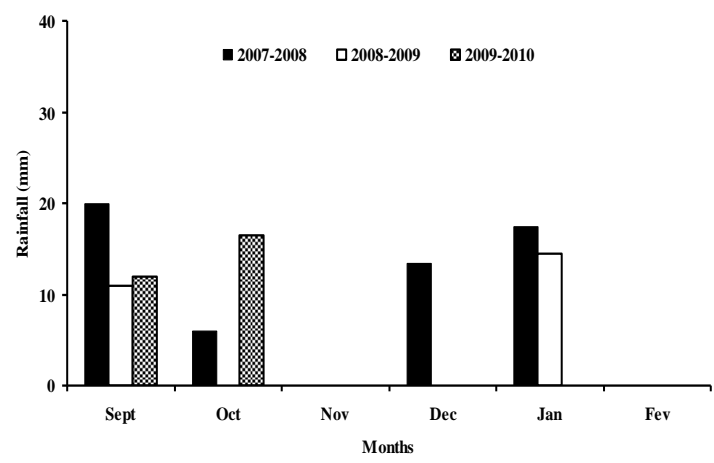

Figure 1. The rainfall received during the carrot cropping periods (2007-2010)

Carrot, native of the region, was planted every year on 15 September, in $8 \times 10 \mathrm{~m}$ plots separated from each other in a randomized complete block design with four replicates and five irrigation treatments. The same experimental area was used for the 3 years and was divided into four blocks with five elementary plots per block. Each elementary plot consisted of fifteen rows. Carrot was surface irrigated with water from a well having an ECi of $3.6 \mathrm{dS} / \mathrm{m}$. Measured amounts of water were delivered to the plots using a hosepipe and water meters.

Fertilizers were supplied for the cropping period in the same amounts; before planting of carrot crop, soil was spread with $16 \mathrm{t} / \mathrm{ha}$ of organic manure. Nutrient supply included $\mathrm{N}, \mathrm{P}$ and $\mathrm{K}$ at rates of 200, 200 and 150 $\mathrm{kg} / \mathrm{ha}$, respectively, which were adopted from the local practices. The $\mathrm{P}$ and $\mathrm{K}$ fertilizers were applied as basal dose before planting. Nitrogen was divided and delivered with the irrigation water in all treatments during early vegetative growth.

Five irrigation regimes were considered: four treatments used the soil water balance (SWB) and consist in delivering total or a fraction of cumulated ETc when readily available water in the root zone is depleted and traditional farmer's method, supplying water with constant amount and frequency. For SWB methods we adopted replacement of $100 \%$ ETc (I100), considered as full 
irrigation, continuous deficit irrigation regimes supplying 80\% (I80) and 60\% ETc (I60), and regulated DI regime where $40 \%$ reduction is applied only during ripening stage (I60-ripening). Farmer method (Farmer) consisted in giving $25 \mathrm{~mm}$ every 7 days from planting till harvest.

The crop evapotranspiration (ETc) was estimated for daily time step by using reference evapotranspiration (ETo) combined with carrot crop coefficient $(\mathrm{Kc})$. The ETo was estimated from daily climatic data collected from the meteorological station, located at Médenine, Tunisia (data not presented) by means of the FAO-56 Penman-Monteith method (Allen et al., 1998). The carrot crop coefficient (Kc) was computed following the single crop coefficient approach.

The soil water balance (SWB) method was adopted for irrigation scheduling using the guidelines No. 56 of the FAO (Allen et al., 1998). To this end a soil water balance (SWB) model was developed to estimates the number of days to evaporate the readily available water (RAW). The model computes the soil water depletion on daily basis and projects the next irrigation event based on the target depletion (35\% of total available water (TAW)). The root depth starts with a value of $0.15 \mathrm{~m}$ at planting and increases linearly with the increase of carrot crop coefficient up to $0.80 \mathrm{~m}$.

At physiological maturity carrot yields were obtained. Forty plants per row within each plot were harvested every year by hand to determine fresh root yield, root number $/ \mathrm{m}^{2}$ and root weight.

Every year, soil samples were collected after harvest of carrot crop. Each elementary plot was sampled with a $4 \mathrm{~cm}$ auger at two points within homogeneous areas from four depths (0-0.20; 0.20-0.40; 0.40-0.60;0.60-0.80 m in depth). Samples were air-dried and ground to pass a mesh of $2 \mathrm{~mm}$ size and were analyzed for ECe.

Water productivity (WP) is generally defined as marketable yield/ET, but economists and farmers are most concerned about the yield per unit of irrigation water applied. Thus, The WP was calculated as follow: WP $\left(\mathrm{kg} / \mathrm{m}^{3}\right)=$ Yield $(\mathrm{kg} / \mathrm{ha}) /$ irrigation water $\left(\mathrm{m}^{3} / \mathrm{ha}\right)$

Analysis of variance was performed to evaluate the statistical effect of irrigation treatments on carrot yields and components, WP and soil salinity using the STATGRAPHICS Plus 5.1 (www.statgraphics.com). LSD test at 5\% level was used to find any significant difference between treatment means.

\section{RESULTS AND DISCUSSION}

Figure 2 illustrates the course of mean daily ETc relative to ETo for three years during the periods of carrot crop. During the first 30 days after plantation of carrot, high ETc values where observed when the wetting of the soil surface by irrigation or precipitation coincides with high evaporative demand. Most of the daily crop ET consisted of soil evaporation, controlled mainly by soil hydraulic properties and solar radiation. This period is characterized by mean values of ETc of about $3.6 \mathrm{~mm} /$ day. The ETc values for the carrot crop were, respectively, 3.1 and $2.2 \mathrm{~mm} /$ day at development and midseason stages. The ETc value at the late stage was about $2.5 \mathrm{~mm} /$ day. At the late stage, where the canopy senescence began, the relatively high ETc value of carrot crop was principally attributed to the important soil evaporation induced by the frequency of irrigation or precipitation and to the relatively high evaporative demand.

Figure 3 illustrates soil water depletion, estimated by the spreadsheet program, under I100 treatment the cropping period of carrot for 3 years. The program develops a water balance and supplies information on the timing and amounts of irrigation events. This figure illustrates also the effect of an increasing root zone on the readily available water. The rate of root zone depletion at a particular moment in the season is given by the net irrigation requirement for that period. Each time the irrigation water is applied, the root zone is replenished to field capacity. Because irrigation is not applied in the 
spreadsheet until the soil water depletion at the end of the previous day is greater than or equal to the readily available water, occasionally plants could be subject to a slight stress on the day prior to irrigation.

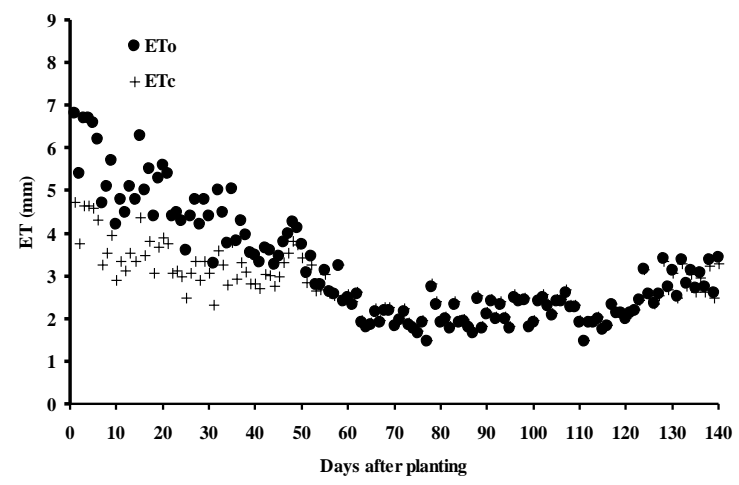

Figure 2. Mean values of daily ETo and ETc during the cropping period of carrot (20072010).

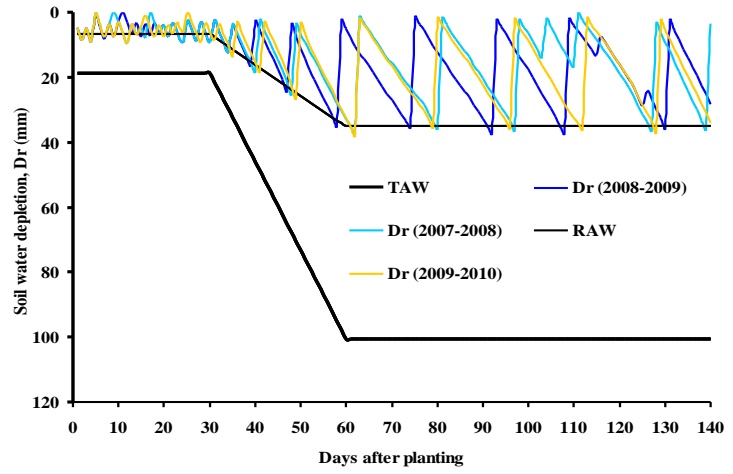

Figure 3. Daily soil water depletion under I100 treatment during the cropping season of carrot (2007-2010).

The initial and final average ECe values (0$80 \mathrm{~cm}$ soil depth) under different irrigation treatments are presented in Figure 4. Initial soil salinity values determined at the time of planting were, respectively, 3.74, 3.2 and 3.7 $\mathrm{dS} / \mathrm{m}$ in the first, second and third year. The results show a decrease in ECe values measured at harvest under all irrigation treatments relative to initial soil salinity during the first year. The decrease of ECe values were due to the leaching of soluble salts by fall and winter rains $(57 \mathrm{~mm})$ (Figure 1). At harvest in 2009 and 2010, the ECe in treatments I100, I80 and I60-ripening decreased as compared to initial soil salinity. However, the ECe values were relatively higher than the initial ECe for I60 and farmer's method despite leaching during the period of fall and winter rains.

The lowest ECe values occurred during the first year, and the highest was attained during the third year. The small ECe in first year was attributable to the leaching that had occurred during both fall and winter periods. The total rainfall during carrot growing season that year was the highest of the three years (Figure 1).

ECe data (Figure 4) shows that there were decreases in the ECe in full irrigation treatment (I100). I60-ripening treatment resulted also in low ECe values. During this 3-year study, the ECe values were not consistently different for I100 and I60ripening treatments. However, higher soil salinity was observed in case of deficit irrigation treatments than full irrigation (I100). ECe values were, in a decreasing order, I60 > I80 > I100. The reason for the higher soil salinity obtained for deficit irrigation treatments may be attributed to little leaching of the soil expected under deficit irrigation conditions. One consequence of reducing irrigation water use by deficit irrigation is the greater risk of increased soil salinity due to reduced leaching (Kaman et al., 2006; Geerts et al., 2008b; Schoups et al., 2005). The highest ECe values were observed for farmer's irrigation method despite the fact that more water was applied in this treatment. Adopting fixed amounts and frequency during the whole growing season may result in applying excess water during the first growing stage and insufficient water during mid and late seasons. Under such situation, leaching of salts could not take place and salts accumulate in the root zone. 


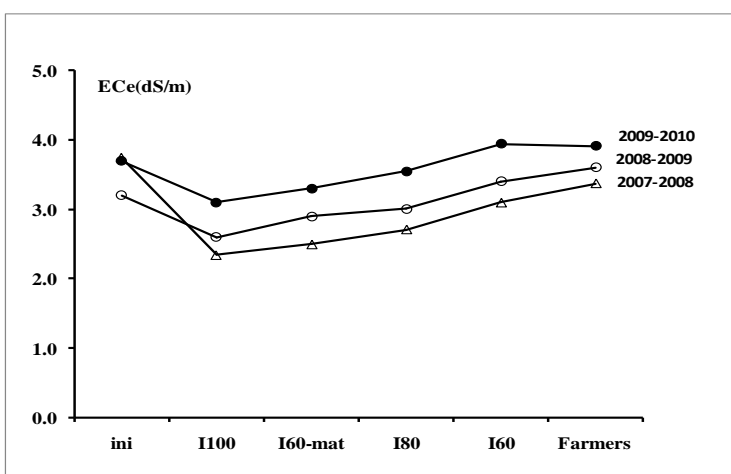

Figure 4. Soil salinity (ECe, dS/m) under different irrigation treatments of carrot.

Low values of ECe under the prevailing climatic conditions were due to the leaching of soluble salts with the received rainfall (Figure 1). The leaching by rain water occurred during fall and/or winter periods. Thus, under actual farming conditions, the adoption of a short productive cycle during the rainy season facilitates the use of saline waters for irrigation and reduces of soil salinization by natural leaching.

Carrot yields data are presented in figure 5 and table 1. Carrot yields over the three years of this study were significantly different between the I80 and I60 treatments (Figure 5). Lower yields were observed for the farmer's method and I60. These two last treatments did not show a statistical difference between them and were considerably lower than that obtained under I100 treatment. In 2007-2008, even though numerically higher yield was observed with the I100 than with the I60-ripening treatments, they were not statistically different. Similar results were observed for these treatments in 2008-2009 and 20092010. However, yields dropped significantly with the I80 and I60 treatments during the three years of the study.

The I60 and farmer's irrigation treatments produced a similar root yield, but the first saved $40 \%$ irrigation water. Also, I80 strategy produces 22 and $29 \%$ more yield than farmer' method. Roots number $/ \mathrm{m}^{2}$ and weight (Table 1) were influenced by the irrigation treatments. The root weight and number for producer's method was lowest while I100 and I60-ripening treatments did not differ significantly from each other.

The decreased root yields in the I60 and farmer's strategies compared to that in the I100 were associated with lower root number $/ \mathrm{m}^{2}$ and root weight (Table 1) as a result of water shortage during the period between fruit-set and harvest. Thus, the increase in yield under I100, I60-ripening and I80 treatments was attributed to improved growth and yield components due to water supply. These results are in agreement with those reported by Paradiso et al. (2002), Imtiyaz et al. (2000) and Hartmann et al. (1986), who obtained higher total marketable, root size and number with $100 \%$ ETc, full irrigation. therefore, water stress should be avoided between fruit-set and harvest, the most critical period of carrot for irrigation.

Higher yields were observed in the first year because of the low soil salinity and the higher amount of rainfall $(57 \mathrm{~mm})$. The differences in yield under I100 and I60ripening treatments were not significant. Due to its effect of reducing the build-up of salinity the I60-ripening treatment resulted in carrot yields comparable with those obtained in I100 strategy.

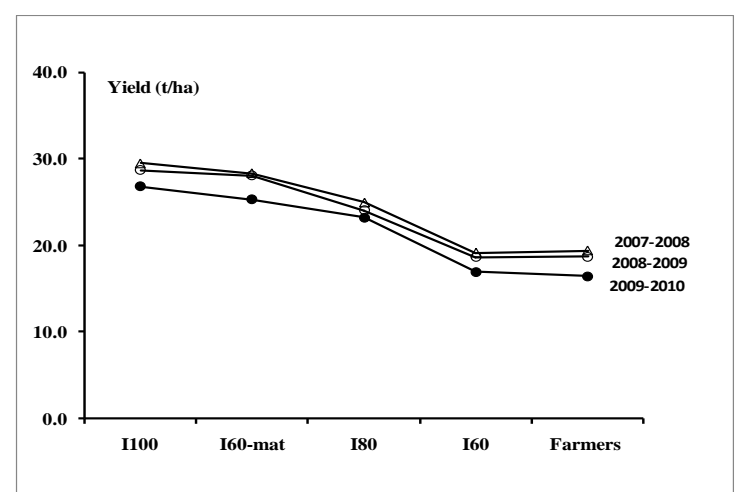

Figure 5. Yields of carrot in relation to the irrigation treatment and the year of production. LSD (5\%): 2007-2008, 2.45; 2008-2009, 2.50 and 2009-2010, 2.62)

The irrigation scheduling based on SWB as in I100 treatment resulted in greater yields as compared to that with fixed frequency and amounts practiced by local farmers. I60 and farmer's strategies resulted in greater salinity 
in the rooting zone than that in I100 (Figure 4). The higher soil salinity levels associated with the I60 and farmer's strategies induced substantial yield reduction of carrot. These results support the use of SWB strategy for irrigation with saline water. Numerous reports recommend the use of SWB strategy for conditions similar to those of the present study (Raes et al., 2002; Nagaz, 2007).

Table 1. Yield components of carrot under different irrigation treatments for the three years of the study (2007-10).

\begin{tabular}{lccc}
\hline Regime & $2007-$ & $2008-$ & $2009-$ \\
& 2008 & 2009 & 2010 \\
\hline \multicolumn{4}{c}{ Root number/m² } \\
I100 & 71 & 70 & 67 \\
I80 & 64 & 59 & 59 \\
I60 & 60 & 55 & 52 \\
I60-ripening & 70 & 68 & 63 \\
Farmer's & 62 & 57 & 52 \\
LSD (5\%) & 4.37 & 5.23 & 5.04 \\
\multicolumn{4}{l}{ Root weight } \\
I100 (g/root) \\
I80 & 41.4 & 41.0 & 40.1 \\
I60 & 35.4 & 40.7 & 39.3 \\
I60-ripening & 24.2 & 33.9 & 32.6 \\
Farmer's & 23.7 & 41.3 & 40.2 \\
LSD (5\%) & 3.63 & 32.8 & 31.6 \\
\hline
\end{tabular}

The lower yields obtained under farmer's method can be attributed to the fact that water was applied in excess of crop needs. Farmer method of application of fixed amount of irrigation water with fixed interval from planting till harvest is often characterized by periods of over- and underirrigation. This may result in nutrients leaching out of the root zone during early stages of growth and low water availability during periods with high water needs, therefore limiting crop growth and yield.

The irrigation scheduling based on crop water requirements and soil characteristics resulted in water amounts and intervals adapted to the crop requirement change during the growing season and then allows for applying irrigation water when needed during the growing season. According to Smith (1985), optimal scheduling is only possible when water supply and irrigation amounts can be managed by farmer. For small farmers with their own water source, as in arid regions of Tunisia where irrigation uses shallow well waters, the capacity to decide moment and water amounts of irrigation can facilitate the adoption of the suitable scheduling.

The amounts of water applied for the carrot from planting to harvest over the three-year period are given in Table 2. The irrigation water amount applied $(100.5 \mathrm{~mm})$ before planting of carrot each year is not included in the total. Total rainfall amounts for the three growing seasons were 57, 25.5 and $28.5 \mathrm{~mm}$ in 2007/2008, 2008/2009 and 2009/2010, respectively. Cumulative reference evapotranspiration over the three year study were 438, 443 and $440 \mathrm{~mm}$, respectively. Less rainfall received and relatively higher evaporative demand resulted in more irrigation amounts applied (Table 2).

When the crop was irrigated at $100 \%$ ETc (I100), irrigation amounts averaged $328 \mathrm{~mm}$ in $2007 / 2008,330 \mathrm{~mm}$ in $2008 / 2009$, and $328.5 \mathrm{~mm}$ in $2009 / 2010$. Compared to the $100 \%$ ETc treatment, 31, 15 and $29.5 \mathrm{~mm}$ of water were saved by irrigation treatment I60-ripening, respectively, in first, second and third year. Similarly, the water savings from the 60 and $40 \%$ of ETc approach (I80 and I60) were 66 and $131 \mathrm{~mm}$ compared to the $100 \%$ ETc treatment. The amount of irrigation water for I100 irrigation treatment was comparable to that reported by (Paradiso et al., 2002).

Water productivity based on fresh root production was expressed as the ratio of root yield at final harvest to the water supply (Figure 6). The WP values reported in this study were similar to those reported for carrot by Imtiyaz et al. (2000) and were affected by irrigation treatments. There is also a variation in WP values between years. For all irrigation treatments, yield was higher in first than the two following years. 
WP values reflect this difference, it varied typically around 3.8-9.7, 3.6-9.4 and 3.4-8.8 $\mathrm{kg} / \mathrm{m}^{3}$, respectively, in first, second and third year.

Table 2. Irrigation water supply under different irrigation treatments during the growing period of carrot for 3 years

\begin{tabular}{lccc}
\hline Regime & \multicolumn{3}{c}{ Irrigation $(\mathrm{mm})$} \\
\cline { 2 - 4 } & $2007-$ & $2008-$ & $2009-$ \\
& 2008 & 2009 & 2010 \\
\hline I100 & 328 & 330 & 328.5 \\
I80 & 262 & 264 & 263 \\
I60 & 197 & 198 & 197 \\
I60-ripening & 297 & 315 & 299 \\
Farmer's & 509 & 518 & 471 \\
\hline
\end{tabular}
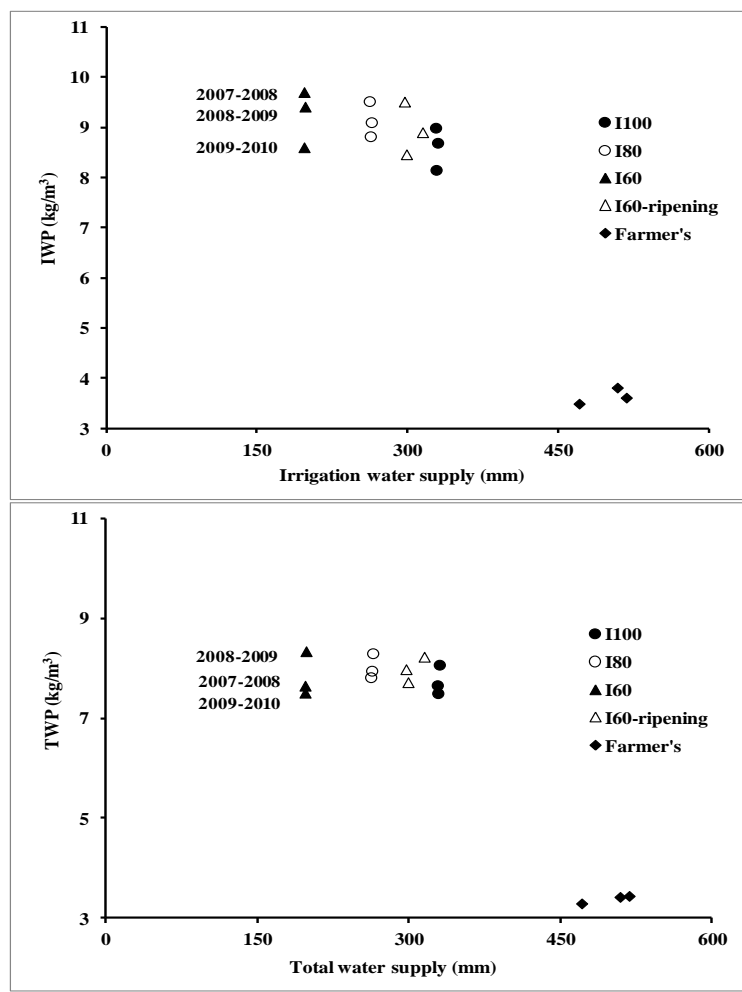

Figure 5. Irrigation and total water productivity (IWP, TWP) under different irrigation treatments during the growing period of carrot for 3 years

For all experiments, the WP with I100 regime was not significantly different from those obtained with I80 and I60-ripening treatments but statistically different from that obtained with I60 and farmer regimes. WP with farmer's method was statistically different from those obtained with I80 and
I60 regimes. These two last regimes did not show a statistical difference between them. Highest IWP averaging $9.70 \mathrm{~kg} / \mathrm{m}^{3}$ was obtained in I60 regime, followed by I80, I60ripening and $\mathrm{I} 100$ regimes with 9.52, 9.51 and $8.99 \mathrm{~kg} / \mathrm{m}^{3}$ in $2007-2008$.

Minimum IWP was obtained from the farmer's treatment as $3.81 \mathrm{~kg} / \mathrm{m}^{3}$ for the first experimental year. In 2008-2009 and 20092010, similar to the previous year, maximum IWP was obtained from the I60 treatment as 9.41 and $8.60 \mathrm{~kg} / \mathrm{m}^{3}$ and followed by $\mathrm{I} 80$, I60-ripening and I100 treatments with IWP of $9.10,8.90$ and $8.69 \mathrm{~kg} / \mathrm{m}^{3}$ versus 8.82 , 8.46 and $8.15 \mathrm{~kg} / \mathrm{m}^{3}$, respectively. Minimum IWP as in the first year were obtained from the farmer's treatment with $3.61 \mathrm{~kg} / \mathrm{m}^{3}$ for the second experimental year and $3.49 \mathrm{~kg} / \mathrm{m}^{3}$ for the third year. The low WUE for the farmer method during the two experiments can be attributed to reduced yields but also to higher irrigation water use.

\section{CONCLUSION}

This study showed that full-irrigated carrot grown over fall-winter period used on average $328-330 \mathrm{~mm}$ of irrigation water for production. The need for irrigation can be reduced by adopting regulated and moderate deficit irrigation (I60-ripening and I80). Full irrigation (I100) and deficit treatments (I60ripening and I80) decreased the soil salinity. Higher soil salinity was maintained with I60 regime and farmer's method. Carrot yields were influenced by irrigation treatments and yields of deficit irrigated treatments (I60 and I80) were significantly lower than those in I100 treatment. Treatment I60-ripening gave also good yields. Deficit irrigation treatments gave lower yields and resulted in higher soil salinity than the full irrigation (I100). The farmer's method was the least efficient and caused higher salinity in the rooting zone and gave the lowest root yields. The water productivity was significantly affected by irrigation treatments. The lowest WP values were observed for the farmer's method, while the highest values were obtained under I60 deficit irrigation 
treatment. I80 seems to represent the best tradeoff between yield and water productivity.

Full irrigation (I100) and deficit irrigation (I60-ripening and I80) strategies offer significant advantage for both carrot yields and WUE and reduce the soil salinity compared to the I60 and farmer's strategies in carrot production. Results of field experiments were demonstrated to the local farmers where the yield increase and savings in irrigation water was fully understood. Thus, full irrigation I100 is suggested for irrigation of carrot crop under the arid conditions of Tunisia. However, under water scarcity, irrigation of carrot could be scheduled using I80 and I60-ripening strategies (DI).

Finally, DI can only be successful if measures are taken to avoid salinization. By using DI strategies, over-irrigation only rarely occurs. Therefore, leaching of salts from the root zone is lower under DI than under full irrigation (Ragab, 1996; Hsiao et al., 2007; Geerts et al., 2008b). The solutions can be found in practice of periodic leaching. The deficit irrigation presents also a great potential to improve water productivity and to control soil salinization by exploiting the natural leaching of salts by the rain. Under such choices natural leaching of salts could help reduce tremendously the cost of drainage.

\section{REFERENCES}

Allen, R.G., Perreira, L.S., Raes, D. and Smith, M. 1998. Crop evapotranspiration: guidelines for computing crop water requirements. Irrig. and Drain. Paper N56, FAO, Italy, pp: 300.

Bernstein L., Francois L.E. and Clark R.A. 1974. Interactive effects of salinity and fertility on yields of grains and vegetables. Agron. J., 66: 412-421.

Doorenbos, J. and Pruitt, W.O. 1977. Crop water requirements. Irrig. and Drain. Paper N²4, pp: 144.

Geerts S., Raes, D., Garcia, M., Condori, O., Mamani, J., Miranda, R., Cusicanqui, J.,
Taboada, C. and Vacher, J. (2008b). Could deficit irrigation be a sustainable practice for quinoa (Chenopodium quinoa Willd.) in the Southern Bolivian Altiplano? Agric. Water Manage., 95: 909-917.

Hartmann, H.D., Werum, H., Bruckuer, U. and Zengerle, K.H. 1986. Effect of irrigation on carrot yield. Gemuse, 22: 6265.

Hsiao T., Steduto, P. and Fereres, E. 2007. A systematic and quantitative approach to improve water use efficiency in agriculture. Irrig. Sci., 25: 209-231.

Imtiyaz M., Mgadla, N.P., Manase, S.K., Chendo, K. and Mothobi, E.O. 2000. yield and economic return of vegtable crops under variable irrigation. Irrig. Sci. J., 19: 87-93.

Jalota S.K., Sood, A., Chahal, G.B.S. and Choudhury, B.U. 2006. Crop water productivity of cotton-wheat system as influenced by deficit irrigation, soil texture and precipitation. Agric. Water Manage., 84: 137-146.

Kaman H., Kirda, C., Cetin, M. and Topcu, S. 2006. Salt accumulation in the root zones of tomato and cotton irrigated with partial root-drying technique. Irrig. Drain., 55: 533-544.

Maas, E.V. 1990. Crop salt tolerance. Ed: Tanji, K.K., Agricultural salinity assessment and management. ASCE Manuals and Reports on Engineering Practice No. 71. American Society of Civil Engineers, New York, pp: 262-304.

Malash, N., Flowers, T.J. and Ragab, R. 2005. Effect of irrigation systems and water management practices using saline and non-saline water on tomato production. Agric. Water Manage., 78: 25-38.

Nagaz, K., Masmoudi, M.M. and Ben Mechlia, N. 2007. Evaluation of on-farm irrigation scheduling: case study of drip irrigated potatoes in Southern Tunisia. Agricultural Journal, 2(3): 358-364.

Nagaz K., Masmoudi, M.M., Ben Mechlia, N. 2007. Soil salinity and yield of dripirrigated potato under different irrigation 
regimes with saline water in arid conditions of Southern Tunisia. Journal of Agronomy, 6(2): 324-330.

Paradiso, R., De Pascale, S. and Barbieri, G. 2002. Effects of water regime and nitrogen supply on yield and mineral composition of carrot. Itlus Hortus, 8(4): 8-13.

Raes, D., Smith, M., De Nys, E., Holvoet, K. and Makarau, A. 2002. Charts with indicative irrigation intervals for various weather conditions. Proceedings of workshop organized by FAO-ICID on: Irrigation Advisory Services and Participatory Extension in Irrigation Management. July 23-24, Montreal, Canada, pp: 65-72.

Ragab, R. 1996. Constraints and applicability of irrigation scheduling under limited water resources, variable rainfall and saline conditions. In: Food and Agricultural Organization of the United Nations (FAO) (ed.), Irrigation Scheduling: from Theory to Practice. Rome, Italy, pp: 149-165.

Schoups, G., Hopmans, J.W., Young, C.A., Vrugt, J.A., Wallender, W.W., Tanji, K.K. and Panday, S. 2005. Sustainability of irrigated agriculture in the San Joaquin Valley, California. Proceedings of the National Academy of Sciences, USA, 102: 15352-15356.

Shannon, M.C. and Grieve, C.M. 1999. Tolerance of vegetable crops to salinity. Sci. Hort., 78: 5-38.

Smith, M. 1985. Irrigation scheduling and water distribution. In: Les besoins en eau des cultures. Actes de Conférence Internationale, INRA, Paris, France, 1114 Septembre 1984, pp: 497-514.

Zhang, Y., Kendy, E., Qiang, Y., Changming, L., Yanjun, S. and Hongyong, S. 2004. Effect of soil water deficit on evapotranspiration, crop yield, and water use efficiency in North China Plain. Agric. Water Manage., 64: 107122. 